\title{
Reference field for the airborne magnetic data
}

\author{
N. V. Fedorova and V. A. Shapiro \\ Institute of Geophysics, 100 Amundsen st., Ekaterinburg, 620016, Russia
}

(Received June 7, 1996; Revised January 14, 1998; Accepted April 9, 1998)

\begin{abstract}
A comparison of satellite and surface surveys of geomagnetic anomalies is performed. A special regional aeromagnetic survey was carried out at the Urals. Different models of the reference field for the region under investigation were studied. A reference field has been constructed using polynomial of 4-th order. The long-wavelength component of the anomalous magnetic field was selected. It is shown that when dividing the magnetic field of the Earth into a main and anomalous parts by spherical harmonic analysis, a large part of the magnetic field from the crust is included within the main field model. A model of the crustal magnetization of the Northern Eurasia is constructed.
\end{abstract}

\section{Introduction}

One of the most important and complicated problems of up-to-date magnetometry on using it for investigation of the Earth's crustal magnetization (especially in the case of longwavelength anomalies) is the reference field. Actually, what is the reference field for the anomalies with the range of some thousand kilometers?

Satellite magnetometry opens new possibilities for the investigations of the crustal magnetization and studies of socalled intermediate-wavelength band (hundreds to thousand kilometers), thus offering insights on the composition, structure and evolution of the lithosphere. One major advantage of orbital satellite magnetic field surveys is their ability to cover a global set of magnetic field measurements of uniform precision at a single epoch. The data set is consistent and free from secular variations.

The goal of the work proposed is to study the applicability of the satellite main field model as a reference field for airborne survey data.

\section{The Comparison of the Airborne and Satellite Magnetic Data}

The aeromagnetic surveys were carried out along seven east- west geotraverses crossing the Urals and neighbouring parts of east European platform and west Siberian plate between $52-72^{\circ} \mathrm{E}$. Five geotraverses with the length up to 1200 $\mathrm{km}$ are the main profiles (the survey heights were 150, 500, 1000, 2000 and $4000 \mathrm{~m}$ above ground) and other two are parallel auxiliary profiles in $50 \mathrm{~km}$ to the north and to the south from the main ones (the survey heights here were 2000 and $4000 \mathrm{~m}$ ). (Shapiro et al., 1986; Fedorova et al., 1989).

Spherical harmonic series (SHS) were used for the analytical representation of the main magnetic field. We studied MGST (Langel et al., 1980a), GSFC (Langel et al., 1982), IGRF-1980 and M102389 (Cain et al., 1989a) as models of the main magnetic field. $F$-total model fields were consistent with the surface aeromagnetic survey data within $25 \mathrm{nT}$

Copy right (C) The Society of Geomagnetism and Earth, Planetary and Space Sciences (SGEPSS); The Seismological Society of Japan; The Volcanological Society of Japan; The Geodetic Society of Japan; The Japanese Society for Planetary Sciences. over the studied area of $50-70^{\circ} \mathrm{N}$ latitude and $50-80^{\circ} \mathrm{E}$.

Thus, for the subsequent analysis we used the MGST model as the satellite data. Figure 1 shows the distribution of residual field computed from uniformly distributed aeromagnetic survey data, referenced to MGST models. This distribution does not follow the normal pattern: the mean is $-50 \mathrm{nT}$ and the standard deviation is $220 \mathrm{nT}$. There is a systematic underestimation of the anomalous field.

For the studied area, the regional reference field has been constructed from the

$$
F(\phi, \lambda)=\sum_{i=0}^{N} \sum_{k=0}^{N} a_{i, k}\left(\phi-\phi_{0}\right)^{i}\left(\lambda-\lambda_{0}\right)^{k}
$$

airborne data (Fedorova et al., 1989). We adopted the polynomials as follows, using gephraphical coordinates.

Here $\phi, \lambda$ are the latitude and longitude of the observation point, $\phi_{0}, \lambda_{0}$ are the coordinates of the central point of the area, $N$ is the degree of the polynomial, and $a_{i, k}$ is the polynomial coefficient.

When the reference field is approximated by a polynomial, the result essentially depends on $N$, the degree of the polynomials. Models of the regional reference fields were computed using third- and fourth-degree polynomials. Regional fields had a good match for the entire area of the aeromagnetic survey: the maximum discrepancy was less than $30 \mathrm{nT}$, and the standard deviation $s= \pm 16 \mathrm{nT}$. Polynomials of the fourth degree were finally adopted as the model of the regional reference field. The statistical estimates of the distribution of the residual field $(\Delta F)$ is presented as a histogram in Fig. 1(b). The distribution in this case showed the normal pattern; the mean $F a=-2 \mathrm{nT}$, the standard deviation $s= \pm 165 \mathrm{nT}$.

We compared this regional reference field with the model of the main field MGST. The difference between the reference field and the MGST main field represents so called intermediate wave length anomaly, which is longer than 1500 km (Fig. 2(b)). The anomaly intensity ranges from $+50 \mathrm{nT}$ on East European platform to $-100 \mathrm{nT}$ at the Urals and the West Siberian platform. The pattern of this anomaly (the highs and lows) is similar to the Magsat satellite residual fields (Fig. 2(a)). The consistent features of all the global 


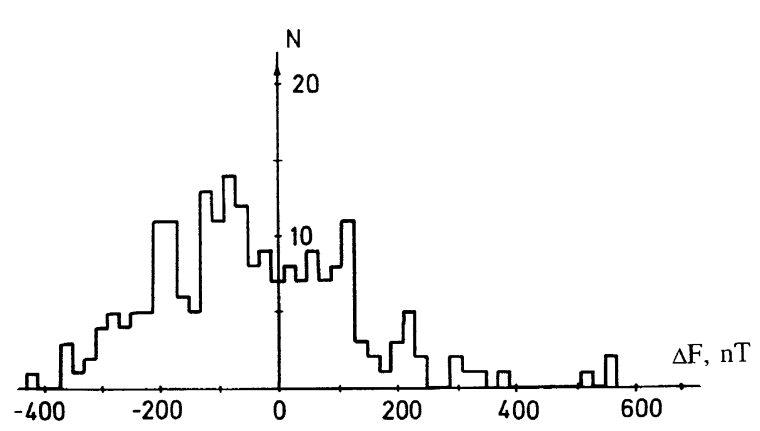

(a)

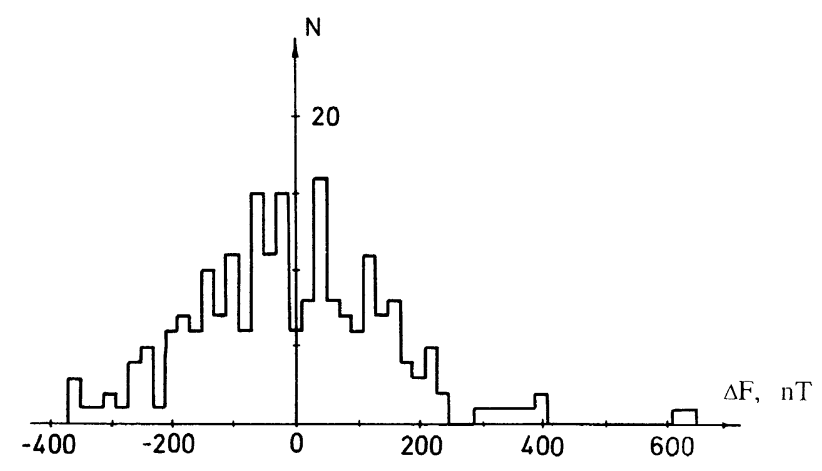

(b)

Fig. 1. Histogramms of the anomalous field from the regional aeromagnetic survey data. (a) Magsat (MGST) main field as a reference; (b) Regional magnetic field as a reference.

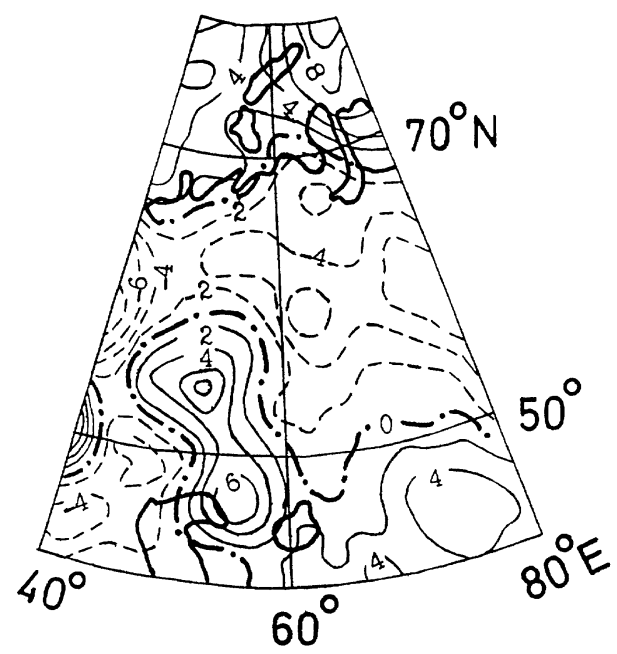

(a)

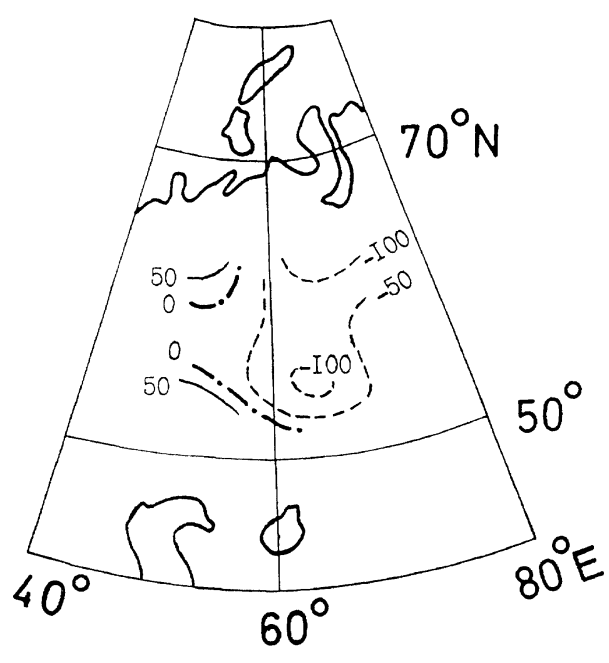

(b)

Fig. 2. (a) Magsat scalar magnetic anomaly map (400 km altitude, $2 \mathrm{nT}$ contour interval); (b) Scalar long-wavelength magnetic anomaly map (2 km altitude, $50 \mathrm{nT}$ contour interval).

magnetic anomaly maps based on Magsat data (Langel et al., 1982; Arkani-Hamed and Strangway, 1985; Coles, 1985; Cain et al., 1989a; Cohen and Achache, 1990) are the large negative anomaly in the West Siberian Basin and the positive anomaly in East of the East European Platform. A more complete comparison of anomalies between airborne and satellite data could be achieved by referencing these results to a common level: recalculating either the aeromagnetic data to an altitude of $400 \mathrm{~km}$ or the satellite data to the Earth's surface. The former method would be preferable, but it is difficult because of the limited area coverage of the aeromagnetic survey and the high altitude of the satellite observations. Cain et al. (1989a) approximated Magsat data by spherical harmonic series up $n=63$ and satellite data were downward continued to ground level. The intensity of the satellite anomalies calculated at the ground level has increased the amplitudes of the anomalies: the positive anomaly in the eastern Europe grew to $+30 \mathrm{nT}$; the negative anomaly in the western Siberia to $-30 \mathrm{nT}$. However, these value are smaller than anomalies identified from aeromagnetic data (Fig. 2(b)).

Thus, when using Magsat main field model as a normal field for the aeromagnetic surveys, we have to correct Magsat reference field because aeromagnetic data include long-wavelength components.

For a number of areas (Canada, USA, Atlantic and Pacific oceans) and even for the whole continent (Australia), there were attempts to compare surface and satellite observations. All these studies showed systematic amplitude discrepancies between satellite data and upward continued surface data (Langel et al., 1980b; Von Frese et al., 1982; Won and Son, 1982; LaBrecque and Cande, 1984; Wellman et al., 1986; Arkani-Hamed and Hinze, 1990; Arkani-Hamed et al., 1995). 


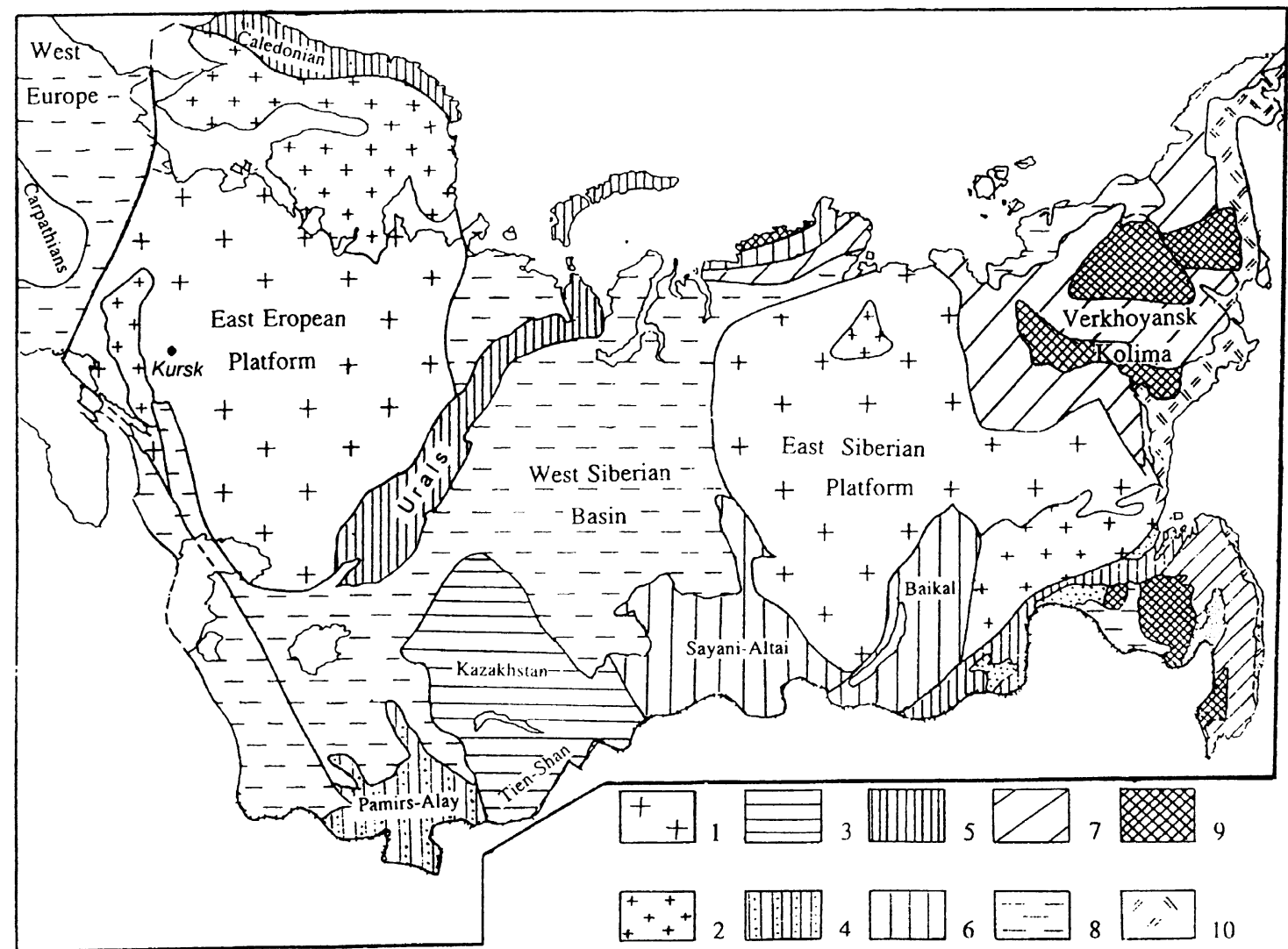

Fig. 3. Tectonic map of the Northern Eurasia. 1. Ancient Precambrian platforms. 2. Archean sheelds. 3-7. Folded belts: 3. Kazakstan- North-Tien-Shan, 4. Pamirs-Alay, 5. Hercynian zones (the Urals, Mongol-Okhotsk, Scandinavia), 6. Sayani-Altai, 7. Verchoyansk-Kolima. 8. Paleozoic cratons. 9. Prepiphean massives. 10. Marginal volcanic massives.

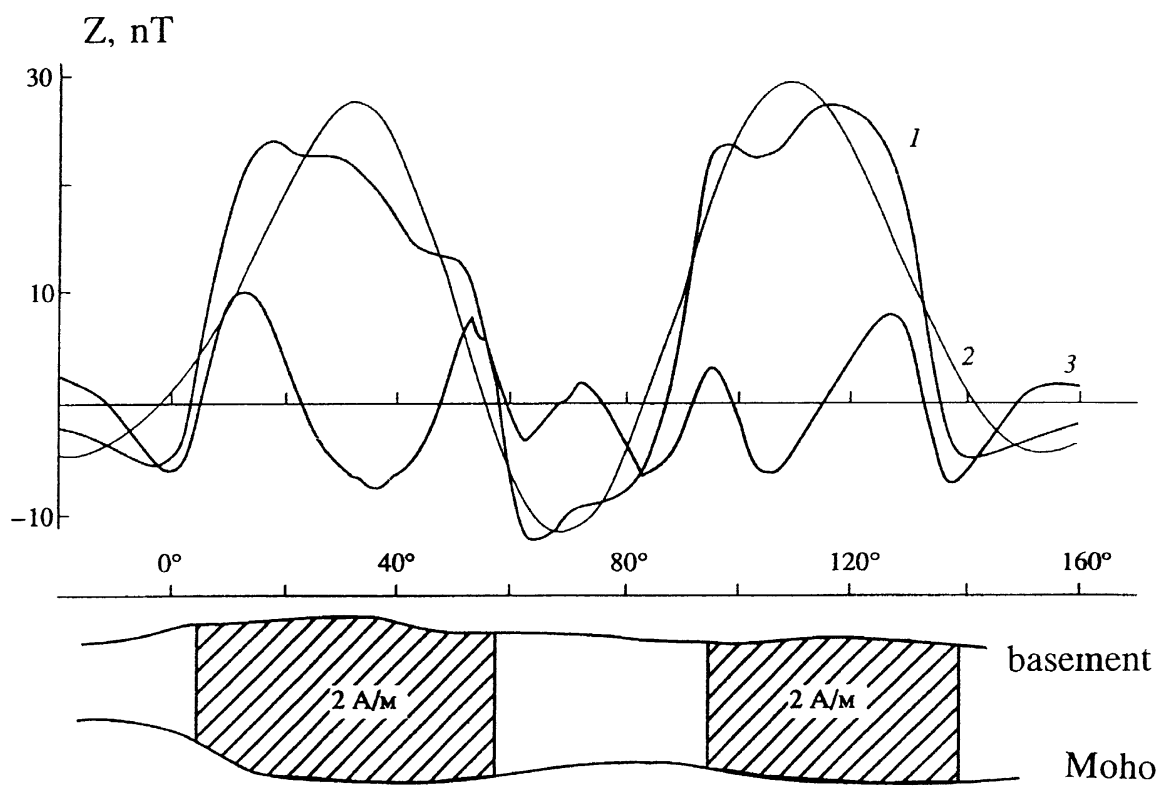

\begin{tabular}{c|c|c|c|c|c}
\hline Atlantic & East Eropean & U & West & East & Verkhoyansk \\
Ocean & Platform & a & Siberian & Siberian & Kolima \\
& & l & Basin & Platform & Orogen \\
\hline
\end{tabular}

Fig. 4. Cartoon depicting the crustal magnetization model for the Northern Eurasia and results of the calculation along profile for latitude $60^{\circ} \mathrm{N}$ and altitude $400 \mathrm{~km}$. 1 - direct effect, 2 - result of the approximation the curve 1 by SHS with degree and order $n=m=13,3$ - residual field, computed as a difference between curves 1 and 2 . 


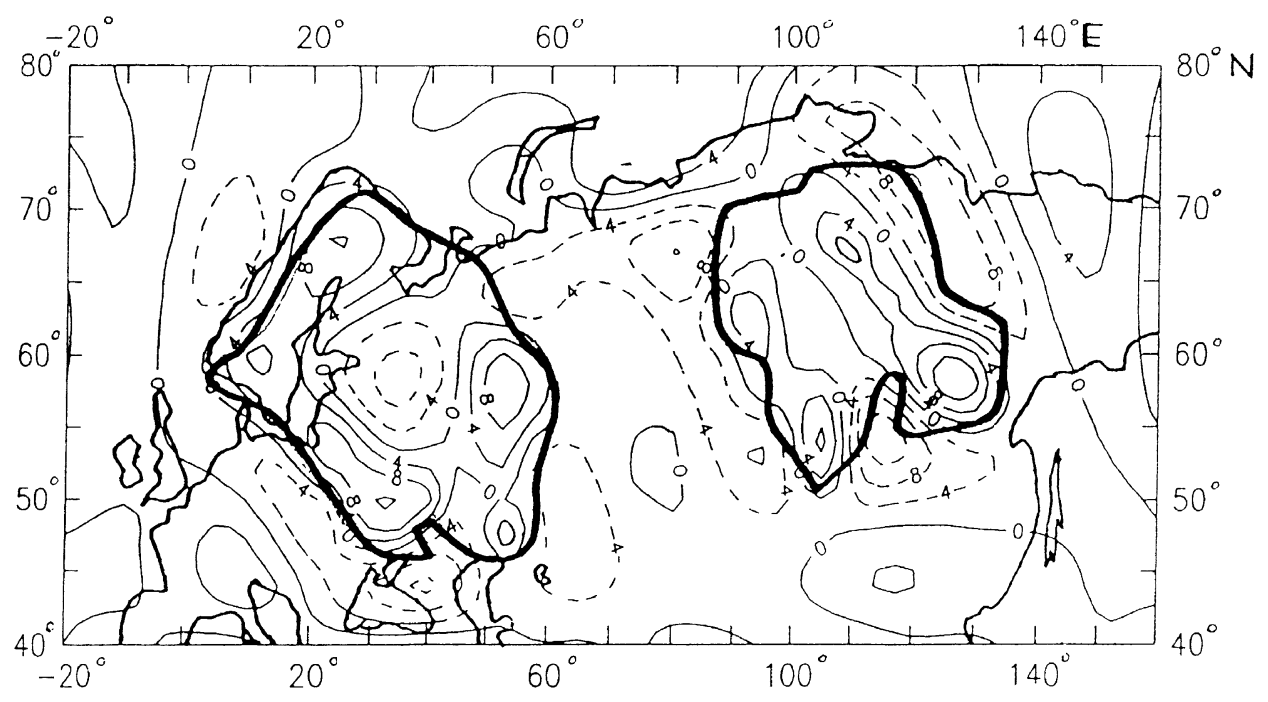

(a)

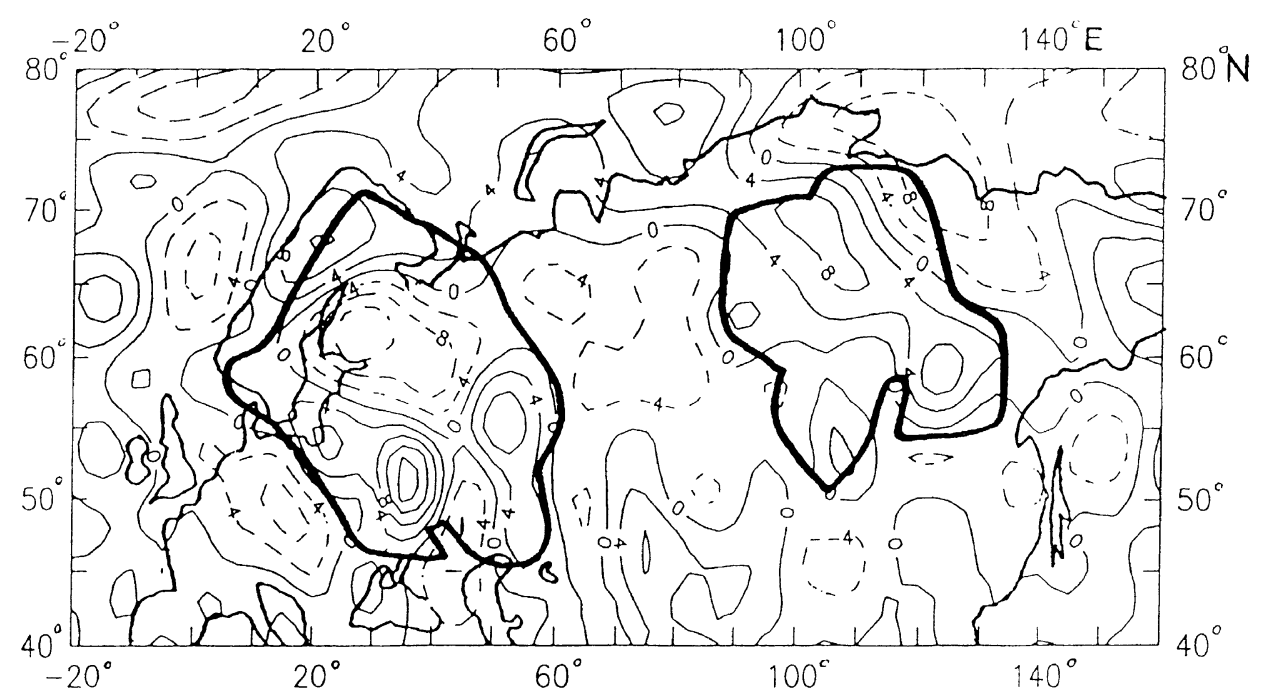

(b)

Fig. 5. The vertical component $Z$ map for Northern Eurasia ( $400 \mathrm{~km}$ altitude, $4 \mathrm{nT}$ contour interval): (a) residual crustal field from the model, (b) Magsat anomalies according to Cain et al. (1989a). Contour of the ancient platforms pictured with a thick curves.

\section{Crustal Sources in the Northern Eurasia}

For East European Platform, Pashkevich et al. (1990), Orluk and Pashkevich (1994) calculated magnetic anomalies at satellite altitude from crustal sources obtained from aeromagnetic data and compared the results with Magsat anomalies. The locations of magnetic highs and lows coincide well, but the intensity of the anomalies differed significantly. Orluk and Pashkevich (1994) concluded that the Magsat normal field for Europe must be corrected.

Over Northern Eurasia, the interpretation of the satellite extended negative magnetic anomalies $(Z$ or $F)$ is a complicated problem: the researchers are forced either to rise the level of the field (Nolte and Hahn, 1992) or to allow the existence of extended rock massifs magnetized against the modern magnetic field (Arkani-Hamed and Strangway, 1985, 1986; Taylor and Ravat, 1995).
One of the major discussions on the Magsat crustal anomaly is the absence of ocean-continent magnetization contrast. The lack of magnetization contrast has been attributed either to the subtraction of these features along with removal of fields from the main field model (Meyer et al., 1985; Langel, 1990; Counil et al., 1991), or to the insufficient resolution (Arkani-Hamed, 1990). Meyer et al. (1985) and Rajaram and Langel (1992) showed that spherical harmonic models do not only represent the core fields, but also include anomalous fields caused by the continent-ocean contrast.

All above facts indicate that the Magsat main field includes a significant part of the lithospheric anomalies. The authors of the Magsat SHS models believe that, in the spectrum of the geomagnetic field a distinct minimum is absent, and that the clear separation of the fields from the core and crust is difficult. Langel and Estes (1982) generally considered that 


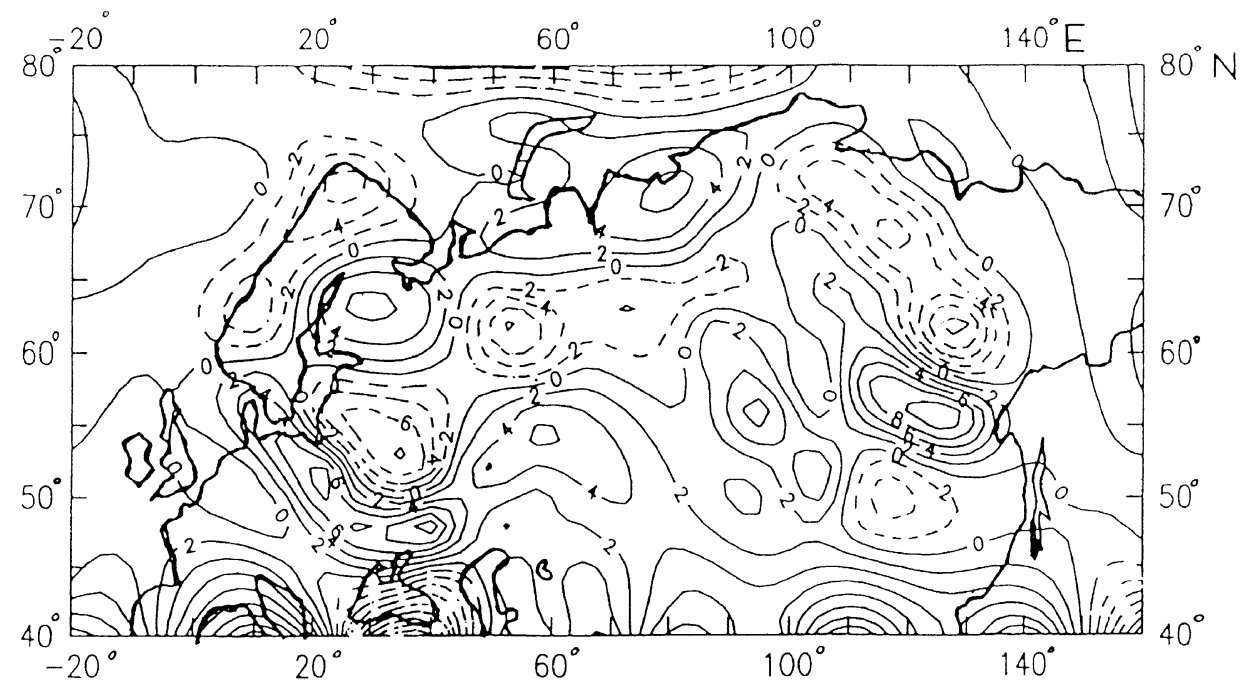

(a)

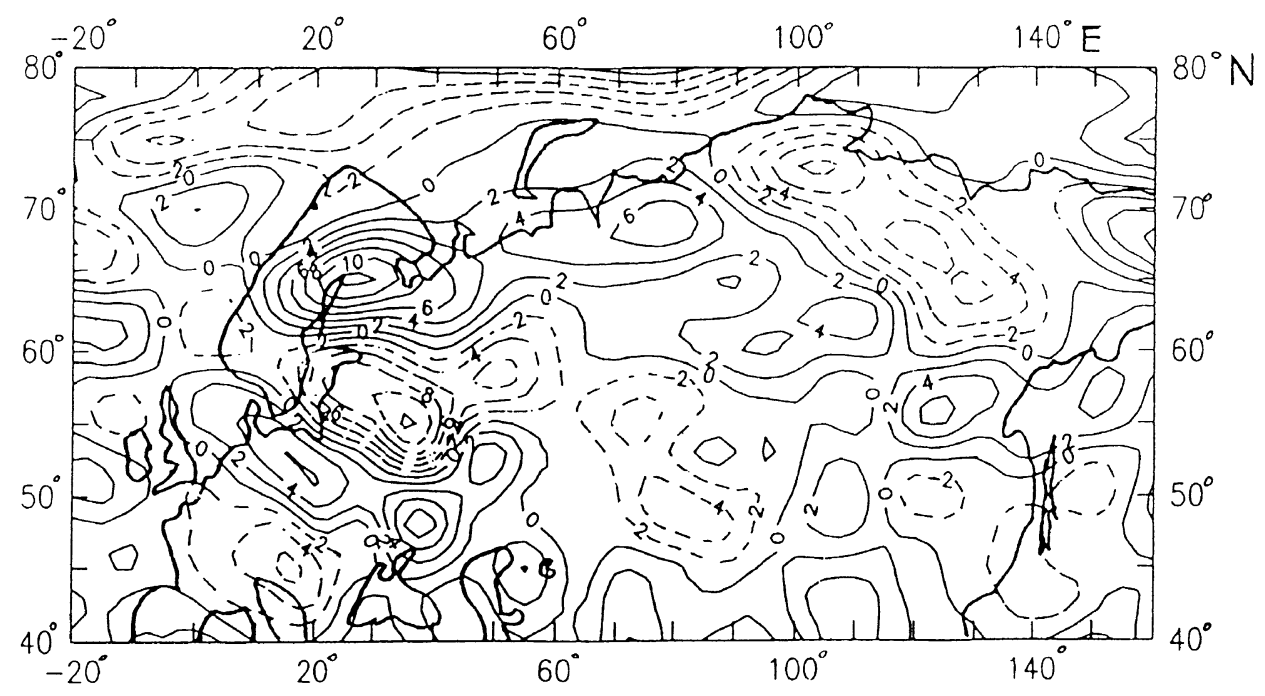

(b)

Fig. 6. The same as Fig. 5 for $X$-component.

a spherical harmonic analysis of the field is dominated by the field from the core up to degree 12, and by the field from the crust above degree 14. Cain et al. (1989b) showed that the point where the energy density of the core and crustal components become equal at the Earth surface is $n=14.2$ and half the crustal power is extrapolated to $n=0$. Magsat anomalies are the residual; anomalies; they are the differences between the observed field and SHS fields with degrees and orders up to $n=m=13$.

In this part of paper we have investigated the problems of separation the main field and anomalies from the large lithospheric sources through SHS by means of modelling of magnetic fields from the sources located in the crust of the East European and West Siberian platforms.

The Eurasian continent is a complex region of varying tectonic styles and large-scale tectonic provinces ranging in age from Archean to Neogene. There are two Precambrian platforms here (the East European and the East Siberian) and the young orogenic provinces-Paleozoic of Western Europe and the Western Siberia, and Mesozoic VerkhoyanckKolima (Fig. 3).

The crust of the ancient platforms is thicker and colder than the crust of younger cratons. According to the seismic data, the thickness of the Paleozoic crust is $30-35 \mathrm{~km}$ while that of the Precambrian crust is $42-55 \mathrm{~km}$ (Milanovsky, 1989). The heat flow of the Precambrian cratons is low (30$\left.50 \mathrm{~mW} / \mathrm{m}^{2}\right)$, while that of younger regions is significantly higher $\left(50-80 \mathrm{~mW} / \mathrm{m}^{2}\right)$ (Chermak, 1993). From the statistical studies on aeromagnetic anomalies, the foundation of Precambrian platform has larger horizontal scale and stronger magnetization than that of younger provinces (Lugovenko, 1974). The mean intensity and horizontal scale of the magnetic anomalies at the ancient craton are estimated as $340 \mathrm{nT}$ and $83 \mathrm{~km}$, while those for younger crust are $160 \mathrm{nT}$ and 56 


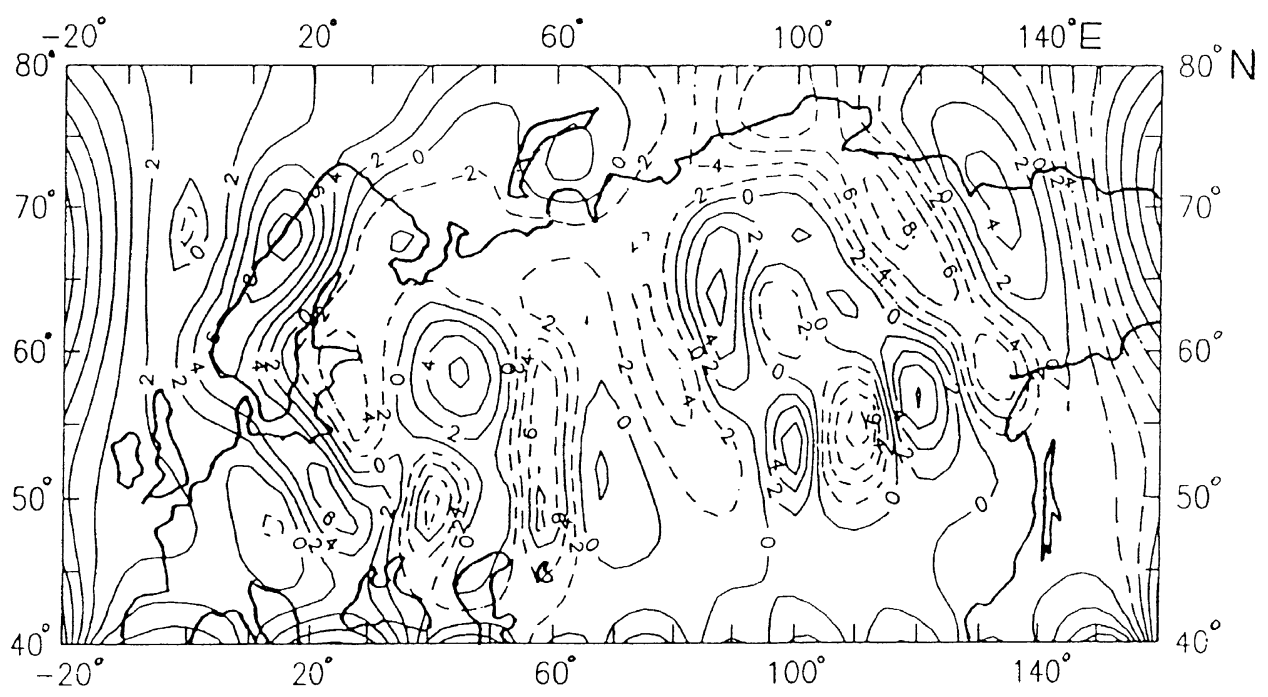

(a)

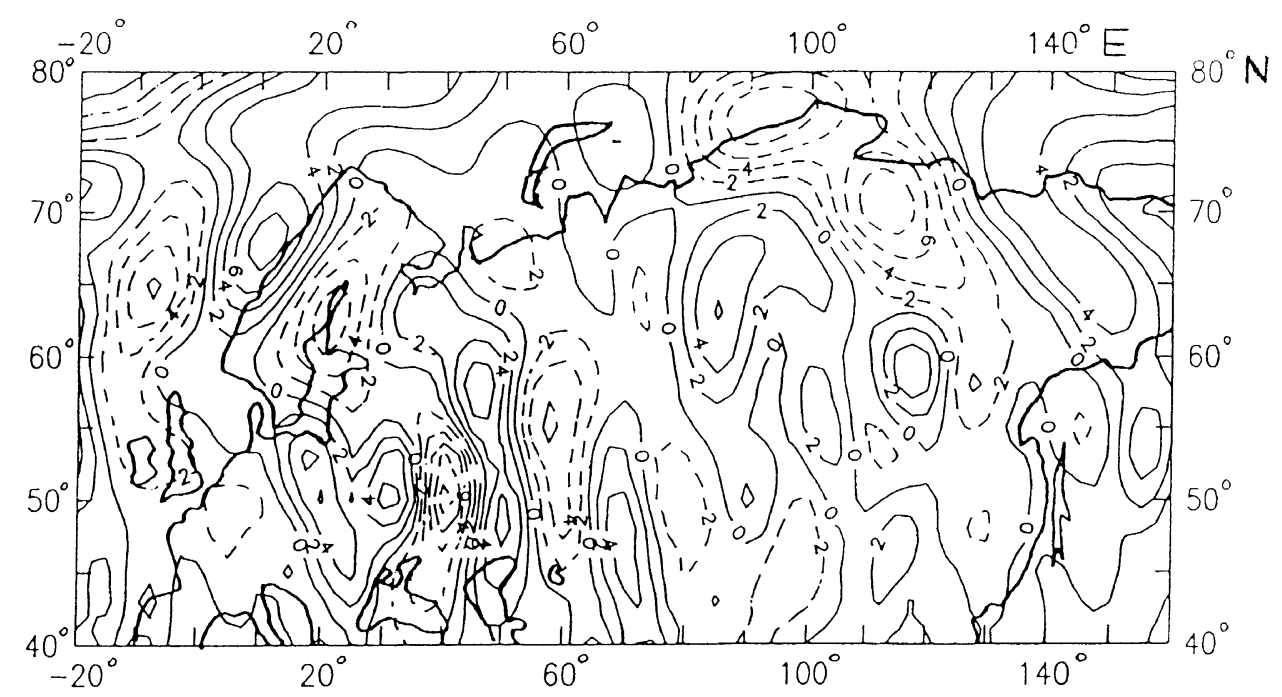

(b)

Fig. 7. The same as Fig. 5 for $Y$-component.

$\mathrm{km}$. Thus, aeromagnetic data may indicate the sharp magnetization contrasts within the continental lithosphere. These contrasts are possibly associated with lithospheric blocks of different ages.

In the lithosphere of the Precambrian platform, there are numerous magnetized blocks, whose distributions are fairly similar. The step-like anomalies over the marginal parts of the platforms are indicative of large average magnetization of the ancient crustal rocks. These allow us to analyze the homogeneous magnetization of the cratons from the aeromagnetic data at the height more than $300 \mathrm{~km}$.

The calculations were done for a spherical globe. The spherical rectangular parallelepipeds were used as magnetic sources elements. The algorithm of magnetic effects of such bodies is described by Manukjan and Starostenko (1984). The geometry of each platform was given as a set of fifty parallelepipeds with the average sizes of $400 \mathrm{~km} \times 400 \mathrm{~km}$.
The objects are located from the top of the crystalline foundation down to the bottom of the crust. Calculations were done for the homogeneous magnetization $(2 \mathrm{~A} / \mathrm{m})$ for all the prisms, except the Kursk magnetic anomaly region (see Fig. 3, in the Southern part of the East-European Platform), which is characterized by extremely high magnetization (6 to $12 \mathrm{~A} / \mathrm{m})$. The direction of magnetization follows the modern field.

It is difficult to tell which part of the long-wavelength anomalies is of crustal origin. To interpret the satellite anomalies, we carried out transformations of the field from synthetic lithospheric sources to Magsat altitude. The residual fields from the model sources were calculated as follow:

(1) the direct field (magnetic field due to the crustal source) was computed,

(2) the approximated field (magnetic field approximated by SHS with a degree and an order $n=m=13$ ) was 


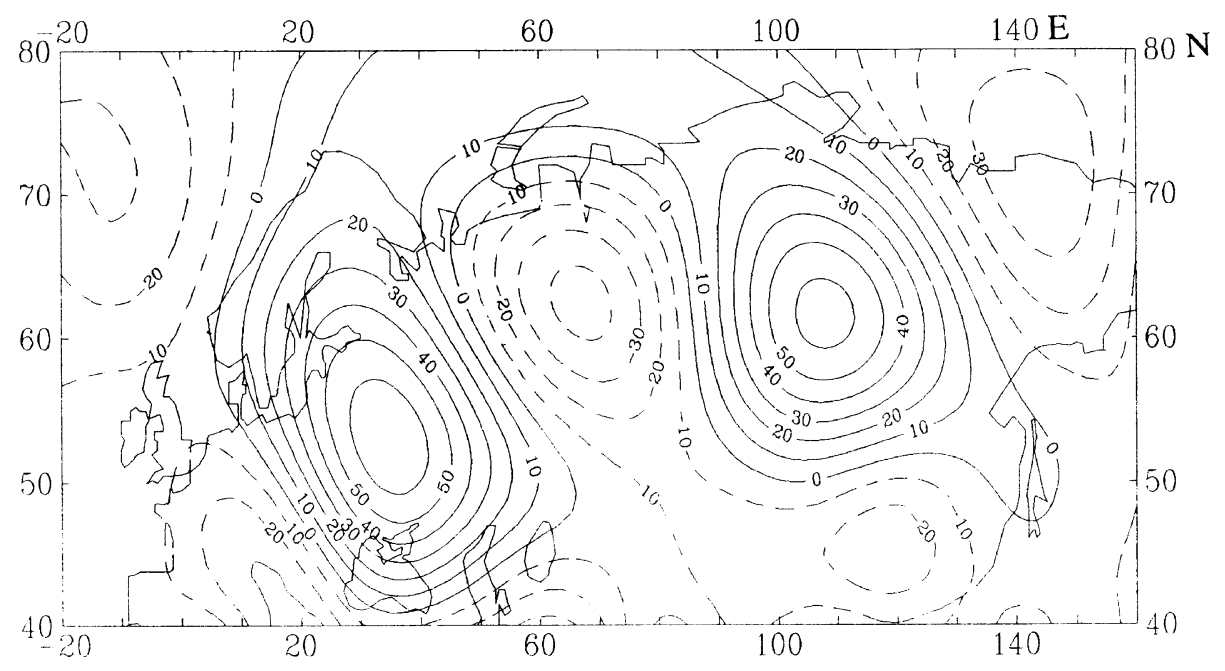

Fig. 8. The long-wavelength vertical component $Z$ at the Earth surface, calculated from terms $n=1$ to 13 .

computed,

(3) the residual field (as a difference between (1) and (2)) was computed.

Figure 4 displays a cartoon depicting the model used in our calculation. The curve 1 is the vertical field component $Z$ from the model, calculated for the altitude of 400 $\mathrm{km}$ along profile at latitude $60^{\circ} \mathrm{N}$. The curve 2 is the approximated fields with SHS. The curve 3 is the residual field. As the residual field is very different from the direct field, it is very difficult to imagine for each platform that this is a field produced by a single homogeneously magnetized object: negative anomalies exist above centers of the regions and the intensity of the positive anomalies considerably decreases. When comparing the residual field from the model (Fig. 5(a)) with the field $Z$ of the Magsat anomalies (Fig. 5(b)), one can note good coincidence of characteristics in both fields. For comparison, we used Magsat data from Cain et al. (1989a). We note significant coincidences of the patterns compiled from the components $X$ and $Y$ (Figs. 6 and 7).

There is a significant contribution to the main fields from the crustal anomalies, which are magnetized in the direction of the modern field. The sources in the Northern Eurasian crust are the rocks of an ancient cratons; magnetic anomalies from these sources contain bands with the wavelength of 8090 degree and intensity of 20-30 nT at the Magsat altitude $(400 \mathrm{~km})$. Contribution of the crustal sources is present in the SHS terms even for degree $n=10$. Thus, results of the modeling show that the spectra of the main geomagnetic field and those of litospheric anomalies are overlapping.

A crustal field decreases rapidly with altitude and it is more pronounced in the near surface data than in the satellite data. The crustal component constitutes less then $0.1 \%$ of the geomagnetic field at altitude $400 \mathrm{~km}$ and is mainly represented by the low spherical harmonics. As seen in Fig. 8, the intensity of long-wavelength crustal components of the synthetic model (which are contained in the terms from $n=1$ to $n=13$ ) is from $-40 \mathrm{nT}$ to $+60 \mathrm{nT}$. This is more than twice larger than that at the satellite altitude (Fig. 5(a)). Thus, it is impossible to use the Magsat main field as a reference field for the regional aeromagnetic data.

\section{Conclusion}

Our study showed that the main field model obtained from the satellite data cannot be used as a reference field for the aeromagnetic survey. We constructed a regional reference field for the study area. We used the 4-th degree polynomial on geographical coordinates. The difference between Magsat model and regional model has indicated that satellite main field model includes long-wavelength component with the length more than $1500 \mathrm{~km}$ and the intensity from $+50 \mathrm{nT}$ to $-100 \mathrm{nT}$ at the ground level.

The comparison between the airborne and satellite surveys showed disagreements. This indicates that a significant part of the lithospheric anomalies is included in the Magsat main field.

The model of the magnetization of the crystalline rocks from the Northern Eurasian crust was constructed. The results of the modelling reveal the significant differences between direct effects from the cratons and residual fields at the satellite altitude.

The Northern Eurasia has a very complex tectonic matrix. Satellite and aeromagnetic data showed that sharp magnetization contrasts exist within the continental lithosphere, associated with lithospheric blocks of different ages. The satellite anomalies over the Western and the Eastern Europe are generated by the sources of the ancient Precambrian EastEuropean platform, where rocks are magnetized in the modern field direction. Magnetic anomalies in the Northern Asia are generated by the crust of the ancient Eastern Siberian craton. According to our estimations, the average magnetization of the rocks here is to $2 \mathrm{~A} / \mathrm{m}$.

The satellite magnetometry opens new possibilities for the investigations of the crustal magnetization. Low-orbit satellites will lead to a further progress in the problem of the separation between core and crustal anomalies. 
Acknowledgments. The authors are grateful to Dr. Chursin who organized the airborne survey at the Urals. We are greatly indebted to Dr. J. Cain, who provided us with the model data M231089. The authors would like to express their thanks to Dr. M. Purucker and other referees for reviewing the paper and giving constructive comments. This research was supported by Fund of Fundamental Research of the Russian Academy Sciences, Grant 96-05-65313.

\section{References}

Arkani-Hamed, J. and W. J. Hinze, Limitations of the long-wavelength components of the North America, Geophysics, 55, 1577-1588, 1990.

Arkani-Hamed, J. and D. W. Strangway, Intermediate-scale magnetic anomalies of the Earth, Geophysics, 50, 2817-2830, 1985.

Arkani-Hamed, J. and D. W. Strangway, Magnetic susceptibility anomalies of lithosphere beneath Eastern Europe and Middle East, Geophysics, 51, 1711-1723, 1986.

Arkani-Hamed, J., J. Verhoef, W. Roest, and R. Macnab, The intermediatewavelength magnetic anomaly maps of the North Atlantic ocean derived from satellite and shipborne data, Geophys. J. Int., 123, 727-743, 1995.

Cain, J. C., Z. Wang, C. Kluth, and D. R. Schmitz, Derivation of geomagnetic model to $n=63$, Geophys. J. R. astr. Soc., 97, 431-441, 1989a.

Cain, J. C., Z. Wang, D. R. Schmitz, and J. Mejer, The geomagnetic spectrum for 1980 and core-crustal separation, Geophys. J. R. astr. Soc., 97, 443447, 1989 b.

Chermak, V., Litospheric thermal regimes in Europe, Phys. Earth Planet. Inter., 79, 179-193, 1993.

Cohen, Y. and J. Achache, New global vector magnetic anomaly map derived from Magsat data, J. Geophys. Res., 95, 10783-10800, 1990.

Coles, R. L., Magsat scalar magnetic anomalies at northern high latitudes, J. Geophys. Res., 90, 2576-2582, 1985.

Counil, J.-L., Y. Cohen, and J. Achache, The global continent-ocean magnetization contrasts, Earth Planet. Sci. Lett., 103, 354-364, 1991.

Fedorova, N. V., V. A. Shapiro, and L. O. Tjurmina, Reference field in regional aeromagnetic surveying and detection of long-wave geomagnetic anomalies, Izvestiya Akademii Nauk SSSR, Earth Phys., 25, 345-350, 1989 (in Russian).

LaBrecque, J. L. and S. C. Cande, Intermediate-wavelength magnetic anomalies over the central Pacific, J. Geophys. Res., 89, 11124-11134, 1984.

Langel, R. A., Study of the crust and mantle using magnetic surveys by Magsat and other satellites. Invited submission for 'Geomagnetic methods and structure of the crust and mantle beneath India', Proc. Indian Acad. Sci. (Earth Planet. Sci.), 99, 581-618, 1990.

Langel, R. A. and R. H. Estes, A geomagnetic field spectrum, Geophys. Res. Lett., 9, 250-253, 1982.

Langel, R. A., R. H. Estes, G. D. Mead, E. B. Fabiano, and E. R. Lancaster, Initial geomagnetic field model from Magsat vector data, Geophys. Res.
Lett., 7, 793-796, 1980a.

Langel, R. A., R. L. Coles, and M. A. Mayhew, Comparisons of magnetic anomalies of litospheric origin measured by satellite and airborne magnetometers over western Canada, Can. J. Earth Sci., 17, 876-887, 1980b.

Langel, R. A., R. H. Estes, and G. D. Mead, Some new methods in geomagnetic field modelling applied to the 1960-1980 epoch, J. Geomag. Geoelectr., 34, 327-349, 1982.

Lugovenko, V. N., Statistical Analysis of Anomalous Magnetic Field, 200pp., Nauka, Moscow, 1974 (in Russian).

Manukjan, A. G. and V. I. Starostenko, Decision of direct magnetometric problem on spherical Earth, Doklady Academii Nauk USSR, 5, 11-17, 1984 (in Russian)

Meyer, J., J. H. Hufen, M. Siebert, and A. Hahn, On the identification of Magsat anomaly charts as crustal part of the internal field, J. Geophys. Res., 90, 2737-2541, 1985.

Milanovsky, E. E., Geology of USSR, part 2, 279pp., Moscow, MGU, 1989 (in Russian).

Nolte, H. J. and A. A. Hahn, A model of the distribution of the crustal magnetization in central Europe compatible with the field of magnetic anomalies deduced from Magsat results, Geophys. J. Int., 111, 483-496, 1992.

Orluk, M. I. and I. K. Pashkevich, Technique and results of the interpretation of the anomalous magnetic field from ground and satellite data, Doklady Academii Nauk Ukraina, 4, 120-123, 1994 (in Russian).

Pashkevich, I. K., V. C. Markovski, M. I. Orluk, S. V. Eliseeva, A. P. Mozgovaij, and S. A. Taraschan, The Magnetic Model of the European Lithosphere, 166pp., Kiev, Naukova dumka, 1990 (in Russian).

Rajaram, M. and R. A. Langel, Magnetic anomaly modelling at the Indo Eurasian collision zone, Tectonophysics, 212, 117-127, 1992.

Shapiro, V. A., A. V. Tsirulsky, N. V. Fedorova, F. I. Nikonova, A. G. Dyakonova, A. V. Chursin, and L. O. Turmina, The anomalous magnetic field and its dynamics used to study the deep structure and modern geodynamic processes of the Urals, J. Geodynamics, 5, 221-235, 1986.

Taylor, P. T. and D. Ravat, An interpretation of the Magsat anomalies of central Europe, J. Appl. Geophys., 34, 83-91, 1995.

Von Frese, R. R. B., W. J. Hinze, J. L. Sexton, and L. W. Braile, Verifications of the crustal components in satellite magnetic data, Geophys. Res. Lett., 9, 293-295, 1982.

Wellman, P., A. S. Murray, and M. W. McMullan, Australian longwavelength magnetic anomalies, BMR J. Aust. Geol. Geophys., 9, $297-$ 302, 1986.

Won, I. J. and K. H. Son, A preliminary comparison of the Magsat data and aeromagnetic data in the continental US, Geophys. Res. Lett., 9, 296-298, 1982.

N. V. Fedorova (e-mail: nf@maglab.mplik.ru) and V. A. Shapiro (e-mail: seva@maglab.mplik.ru) 